\title{
AC 2012-3496: SURVEY OF CIVIL ENGINEERING ASSESSMENT CHANGES IN RESPONSE TO REVISED ABET CE PROGRAM CRITERIA
}

Dr. Ryan Fries, Southern Illinois University, Edwardsville

Ryan Fries is an Assistant Professor of civil engineering at Southern Illinois University, Edwardsville, where he specializes in transportation engineering. He is dedicated to continually improving the education of his students and has been recognized nationally, regionally and locally for his teaching. In addition to his teaching and research activities, he is a member of his department's assessment committee.

\section{Miss Sree Kalyani Lakkaraju, Southern Illinois University, Edwardsville}

Sree Kalyani Lakkaraju was born on Oct. 7, 1990. She was born and brought up in India. She graduated in civil engineering from Chaitanya Bharathi Institute of Technology, Hyderabad, India. She joined Southern Illinois University, Edwardsville in Fall 2011 to pursue a master's of science in civil engineering with specialization in structural engineering. She is an active member in American Society of Civil Engineering.

Dr. Brad Cross, Southern Illinois University, Edwardsville Susan M. Morgan, Southern Illinois University, Edwardsville

Susan Morgan is currently a professor in and the Chair of the Department of Civil Engineering at Southern Illinois University, Edwardsville. She earned her B.S. in civil engineering from Southern Illinois University, Carbondale and her Ph.D. in environmental systems engineering from Clemson University.

\section{Dr. Andrea L. Welker, Villanova University}

Andrea L. Welker, P.E., is an Associate Professor in the Department of Civil and Environmental Engineering at Villanova University. Welker teaches a variety of geotechnical undergraduate and graduate classes, including foundation design and geosynthetics. Her research focuses on the geotechnical aspects of stormwater control measures. In addition to teaching and performing research, she is the assessment chair and study abroad advisor for her department. 


\section{Survey of Civil Engineering Assessment Changes in Response to Revised ABET CE Program Criteria}

\section{Abstract}

In 2008, ABET, Inc. revised the "Program Criteria for Civil Engineering (CE)" included in the Criteria for Accrediting Engineering Programs to better reflect the Civil Engineering Body of Knowledge for the $21^{\text {st }}$ Century. CE faculty at Southern Illinois University Edwardsville conducted a nationwide survey during the summer of 2011 using the American Society of Civil Engineers' Department Heads Council list serve to determine if other CE Departments were making changes in their programs or assessment plans in response to the revised criteria. In the US there are 224 accredited CE programs; 57 departments responded to the survey, which represents $25 \%$ of all accredited programs. Findings indicated that more than a third (22 of 57) plan to require one additional basic science course and others (18 of 57) already required this additional basic science course. Respondents frequently (32 of 57) defined the phrase, "in more than one civil engineering context" as meaning students can design in transportation, structural, environmental and geotechnical areas. Lastly, departments commonly include basic concepts in management, business, public policy, and leadership into their capstone courses (39 or 57), student chapter activities (16 of 57), and seminar courses (14 of 57). These findings can provide guidance to $\mathrm{CE}$ departments interested in assessing student outcomes from the CE Program Criteria, specifically department heads/chairs and faculty active in assessment.

\section{Introduction}

During summer 2011, the Civil Engineering (CE) Department at Southern Illinois University Edwardsville launched a survey to investigate best practices for adapting to the recent changes in the ABET Civil Engineering Program Criteria. Although these Program Criteria do not require assessment in the form of student outcomes, our department for example, considers them valuable enough to include in our student outcomes. The changes are summarized as follows:

1. Mathematics and Science Program Criterion:

NEW: the ability to apply knowledge of mathematics through differential equations, calculus-based physics, chemistry, and at least one additional area of basic science, consistent with the program educational objectives PREVIOUS: proficiency in mathematics through differential equations, probability and statistics, calculus-based physics, and general chemistry

2. Technical Areas Program Criterion:

NEW: the ability to apply knowledge of four technical areas appropriate to civil engineering

PREVIOUS: proficiency in a minimum of four recognized major civil engineering areas 
3. Design Program Criterion:

NEW: the ability to design a system, component, or process in more than one civil engineering context

PREVIOUS: an ability to perform civil engineering design by means of design

experiences integrated throughout the professional component of the curriculum

4. Breadth Program Criterion:

NEW: the ability to explain basic concepts in management, business, public

policy, and leadership; and explain the importance of professional licensure PREVIOUS: an understanding of professional practice issues such as: procurement of work, bidding versus quality-based selection processes, how the design professionals and the construction professions interact to construct a project, the importance of professional licensure and continuing education, and/or other professional practice issues.

ABET Civil Engineering Outcomes and Program Criteria are part of a living document. As civil engineers continue to define the needs of future engineers through documents such as the American Society of Civil Engineers (ASCE) Body of Knowledge (BOK) ${ }^{1,2}$, these outcomes and criteria are updated by $\mathrm{ABET}^{3}$. In response to the most recent update of the ABET Civil Engineering Program Criteria, the objective of this study was to find how civil engineering departments in the United States:

- measure the multiple items in the new mathematics and science program criterion,

- interpret "the ability to apply" within the new technical areas program criterion,

- assess differently because of the new wording for the design program criterion and interpret the meaning of "context" for this criterion, and

- perceive the motivation behind the significant changes to the breadth program criterion so faculty can best meet the spirit of the revised document, and include management, business, public policy, and leadership into their courses.

\section{Background}

As the profession of civil engineering continues to evolve so do the number and type of education and assessment tools we use. Many previous studies have examined the impact of changes to CE education with respect to the breadth of material ${ }^{4-11}$, the depth of design and technical learning ${ }^{12-13}$, and how each of these are assessed ${ }^{14-17}$.

\section{A. Breadth of CE Programs}

Successful engineers of the $21^{\text {st }}$ century must master a diverse set of professional skills in addition to technical skills. Although previous work has found that undergraduate programs generally meet the outcomes specified in the first edition of the $\mathrm{BOK}^{4}$ (BOK I), continued efforts to improve the quality of future engineers and their education motivates steady research on the topic. Recent work has examined several of these professional skills that provide engineers' breadth, including knowledge of sustainability, professionalism, humanities, and social sciences.

Previous work has found that most department heads agree that sustainability is an important topic to future civil engineers ${ }^{5}$. Unfortunately, full curriculums and already-limited resources 
are common problems for increasing sustainability content in classes ${ }^{5}$. A study at the University of Utah found that a dedicated course on sustainability as well as coverage in several other courses is required to improve student comprehension on the topic ${ }^{6}$. Others propose that concept maps are a valuable tool for increasing the awareness of students about "green" engineering methods ${ }^{7}$.

To include sustainability throughout their curriculum and overcome the limitations of resources, the University of Vermont used grant funding to support curriculum changes that enhance sustainability comprehension by infusing systems engineering thinking into several courses. As systems engineering encourages a holistic analysis, it integrates well with consideration of sustainability $^{8}$.

ABET refers to professional skills in engineering in ABET Criterion 3 outcomes h to k. Previous work has found that these skills may help budding engineers to succeed in the professional environment. Previous work has found that the ABET professional skills can be taught and mastered as a part of modern engineering education; however, they also found that these skills are assessed to varying degrees ${ }^{9}$. Some schools have developed a specific course on professionalism, such as "Professionalism in the Workplace" at the State University of New York Institute of Technology ${ }^{10}$ and "CEE Professional Practice" at Villanova University ${ }^{11}$. Both of these universities reported that students were able to obtain the desired attributes, betterpreparing them for their careers.

The current $\mathrm{CE}$ program criteria are more reflective of the BOK I as opposed to the second edition of the BOK (BOK II). The BOK I had 15 outcomes, while the BOK II has 24. The BOK II divides the 24 outcomes into the following categories: four foundational, 11 technical, and 9 professional. There is overlap between the outcomes described in both editions of the BOK and the outcomes included in ABET's criterion 3 (a-k). The BOK II is also more closely tied to Bloom's taxonomy, as is reflected in the careful choice of active verbs to indicate the level of achievement expected for each outcome. Although the BOK II introduced nine more outcomes, there was no significant increase in the scope of outcomes. Rather, the outcomes were clarified and specificity was improved. The emphasis on the natural sciences, the humanities, sustainability, globalization, public policy, risk, and uncertainty was increased.

To address the changes from the BOK I to BOK II the CE program at The University of Texas at Tyler adopted a methodology to address this issue using rubrics on multiple assignments within a course to demonstrate each criterion. The results suggested that if faculty have a better understanding of the average student competence of humanities and social sciences entering their classes, they can more effectively include these skills into engineering solutions throughout their course. This method of using assignments throughout the curriculum allowed faculty to understand how students were building their competence throughout their collegiate careers to obtain the final desired level of performance ${ }^{12}$.

\section{B. Depth of CE Programs}

There is also motivation to ensure students are obtaining more depth on key topics, particularly engineering design. One university implemented a converging-diverging model of design for a sophomore -level course on engineering design and technical writing. This course initially used 
a semester long design project, but faculty identified that many student teams made important decisions without any prior analysis and chose a design without investigating alternatives. Thus, they replaced it with a sequence of design projects and introduced the converging-diverging model of design. Faculty worked as teams on assessing the design and later compared it with previous student design procedure to derive a comparative analysis. They found that this new course structure accomplished the goals of improving students' design skills and enhanced the habit of making decisions on the basis of quantitative analysis ${ }^{13}$.

Faculty at another university collectively worked on improving the depth of learning in a firstyear engineering courses through a feedback process. Students took a mastery exam in chemistry, physics, mathematics, and computer sciences and faculty analyzed the results using the Item Response Theory, the basis of the feedback process. This theory helped to determine student abilities in each subject area. The different engineering faculty co-teaching the course used these exams results for continuous improvement of the curriculum both within and outside of the school of engineering. Because the mastery exam was developed in collaboration with faculty from chemistry, physics, mathematics, and computer sciences, the findings led to constructive relationships between the school of engineering and these departments and accurately directed program and course improvement ${ }^{14}$.

\section{Assessment of CE Outcomes and Criteria}

There are several categories of tools commonly used to assess student outcomes and program criteria. These tools can include attitudinal measures such as surveys, student work assessed with rubrics, and criterion-referenced evaluations such as results of the Fundamentals of Engineering (FE) Exam. One school used a web-based system to survey alumni about the programs educational objectives as per EAC-ABET. The results obtained from the survey provided the department with information to drive changes in curriculum, budget expenditures and to guide the senior design projects ${ }^{15}$. Other studies have used surveys to gather student opinions on their level of knowledge ${ }^{6,8}$.

The assessment of student work is a common method for evaluating both students and programs. Several papers note the use of student assignments for assessment including 8, 10-12, 16, and 17. The structure and topic of these assignments is specific to the outcome and course being assessed.

Recent work using criterion-referenced evaluation tools have been reported by Lamar University and New Mexico State. Overall, the findings of the investigation by Lamar University indicate that the use of the FE exam to measure student performance yields considerable data for comparison purposes that may be utilized to assess and improve an engineering program ${ }^{18}$. On the basis of statistical analyses, student performance in the fluid mechanics section of the FE exam has improved in response to the continuous improvement efforts undertaken by the Civil Engineering Department at New Mexico State University ${ }^{19}$. 


\section{Methodology}

In summer 2011, faculty at Southern Illinois University Edwardsville developed a web-based survey to investigate how other U.S. Civil Engineering Departments were planning to address the updated ABET Program Criteria. The researchers organized the questions by the four changes identified in the introduction of this paper. Overall, this brief survey included five questions about the responding department and seven questions about each department's plans for changes in response to the new Program Criteria.

The survey was distributed using the ASCE Department Heads Council email list serve in July 2011 and responses were collected through the end of August. The researchers screened the data to identify if there were multiple responses from any one person or from any schools, finding none. The following section describes the compiled survey findings.

\section{Survey Participant Demographics}

Overall, faculty at 57 universities responded to the survey. The participants came from a variety of backgrounds as illustrated in Figure 1. Note that some survey participants fulfilled more than one role, for example serving as department head and assessment chair. The "other" category included participants such as Director of Assessment, Associate/Assistant Department Head, Department Chair during previous ABET visit, ABET Evaluator, Director for Undergraduate Studies, and Professor.

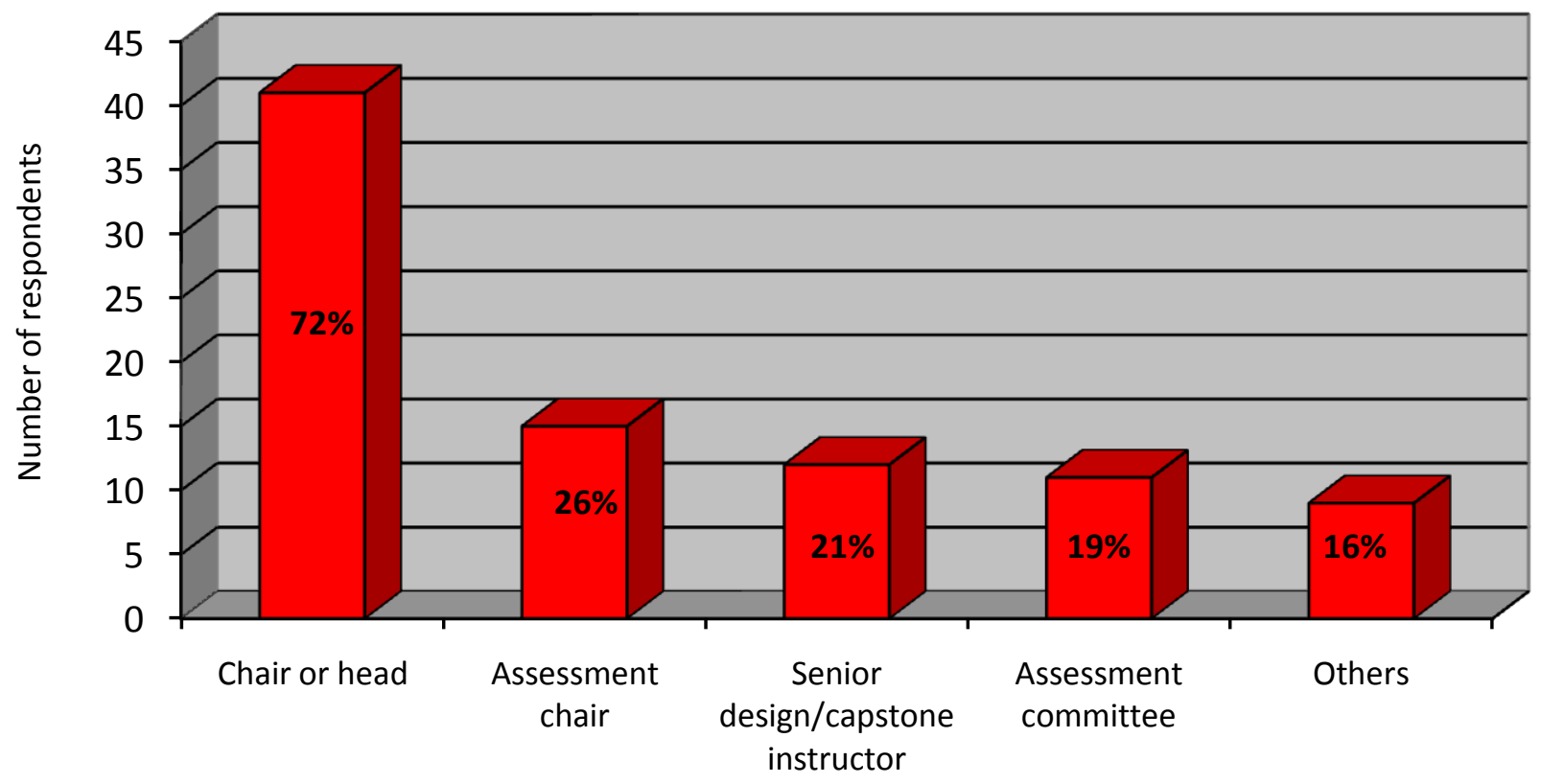

Figure 1: Roles of survey respondents

(Note: Because survey participants could select multiple categories, the percentages shown on the bars add to more than 100 percent. These percentages refer to how many selected each option compared to the total number of participants) 
The survey participants also represented a variety of size, type, and school locations throughout the US. Figure 2 illustrates the location of institutions responding to the survey.

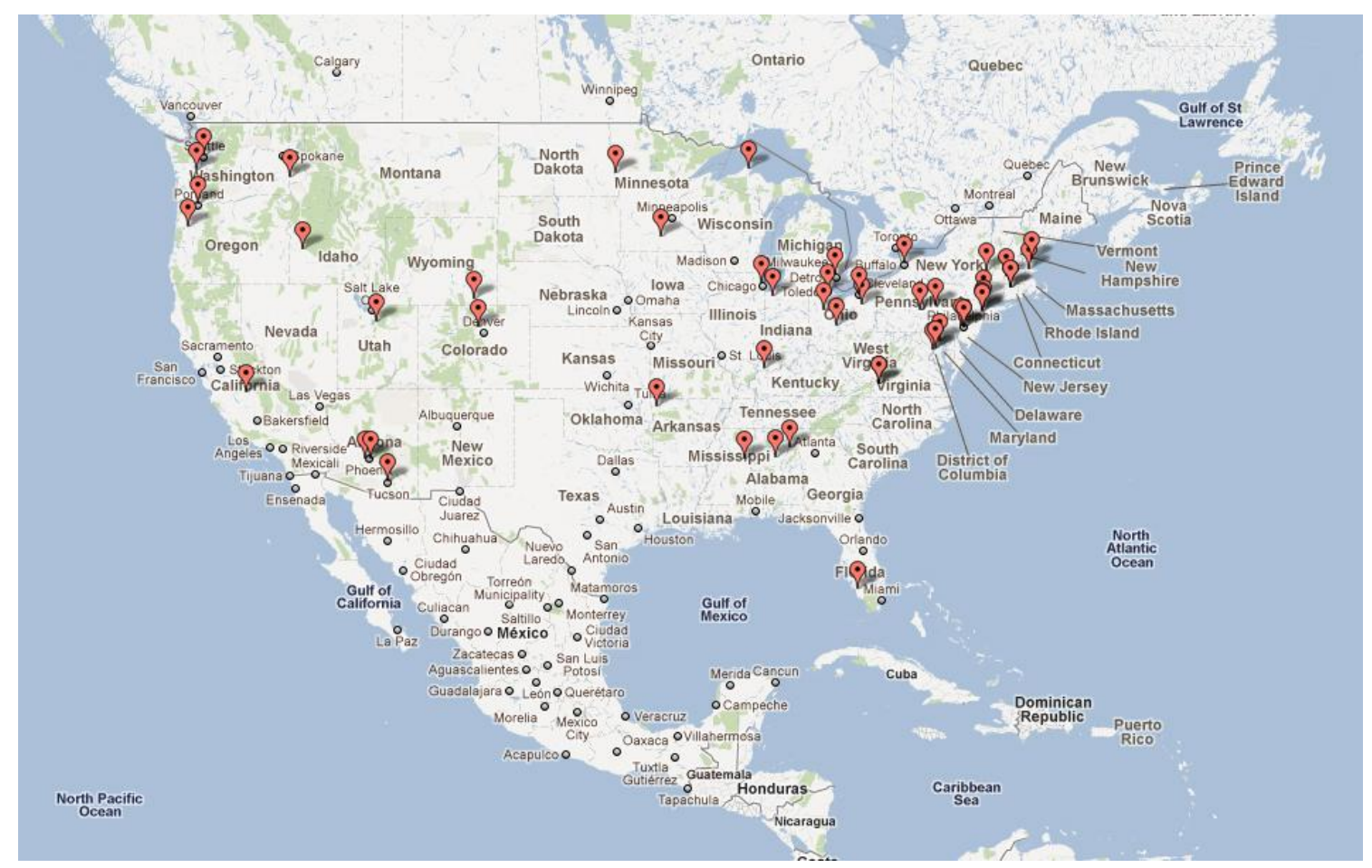

Figure 2: Geographic distribution of respondents (Google maps)

\section{Findings for Revised CE Mathematics and Science Program Criterion}

NEW: the ability to apply knowledge of mathematics through differential equations, calculus-based physics, chemistry, and at least one additional area of basic science, consistent with the program educational objectives

PREVIOUS: proficiency in mathematics through differential equations, probability and statistics, calculus-based physics, and general chemistry

The survey first asked how different departments planned to measure the multiple parts within the revised mathematics and science criterion. The questions allowed participants to select all options that applied and Figure 3 shows that many other departments primarily (41 participants or $72 \%$ ) assess the revised criterion as outcomes in multiple courses and use FE scores (27 participants or 47\%), 22 selecting both. 


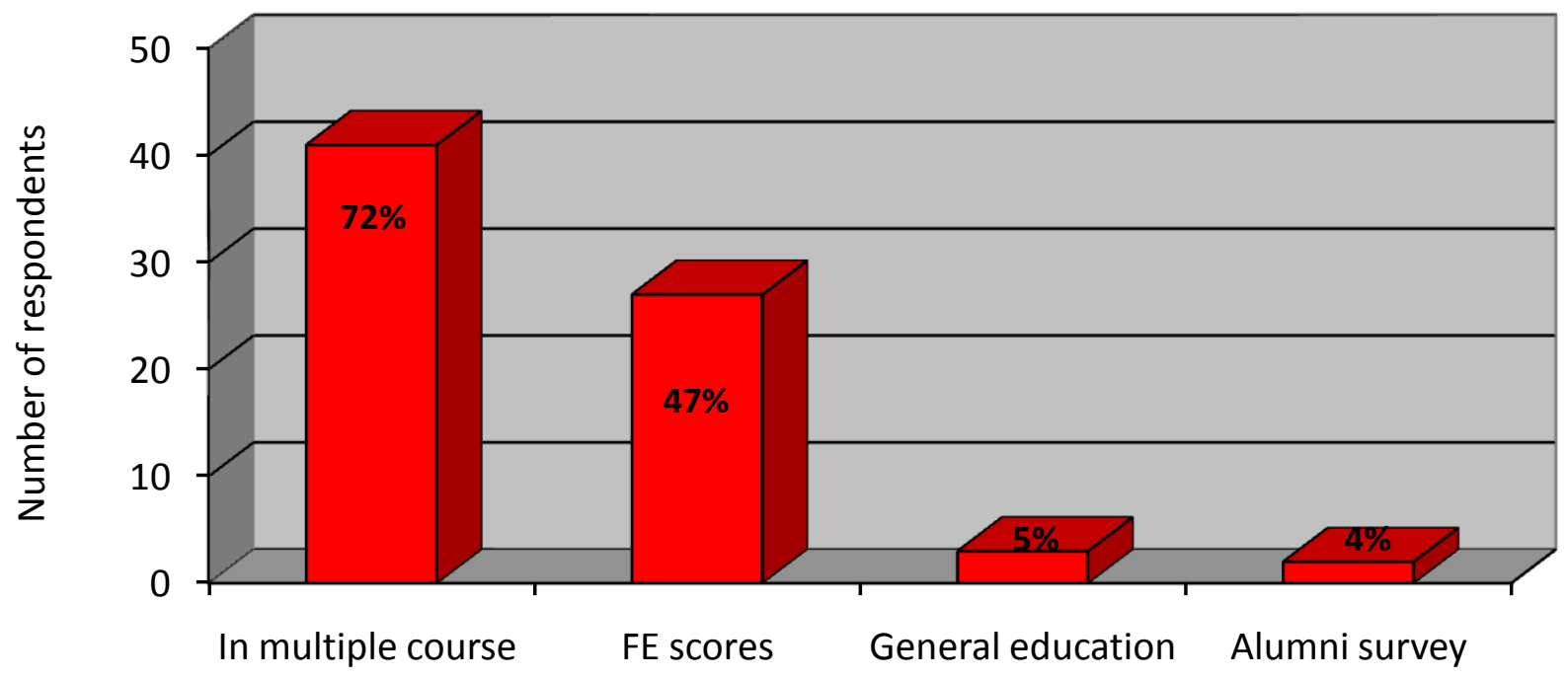

Figure 3: Measuring revised mathematics criterion in CE programs

(Note: Because survey participants could select multiple categories, the percentages shown on the bars add to more than 100 percent. These percentages refer to how many selected each option compared to the total number of participants)

Anticipating that several departments would measure this criterion in several courses, the next question asked how the measurement was conducted within courses, specific to the mathematics criterion. Figure 4 displays the findings, indicating that the most common method is evaluating multiple student assignments within a course (28 participants or 49\%). Respondents noted that assessment of student mathematics outcomes is challenging because non-CE departments traditionally teach these courses. 


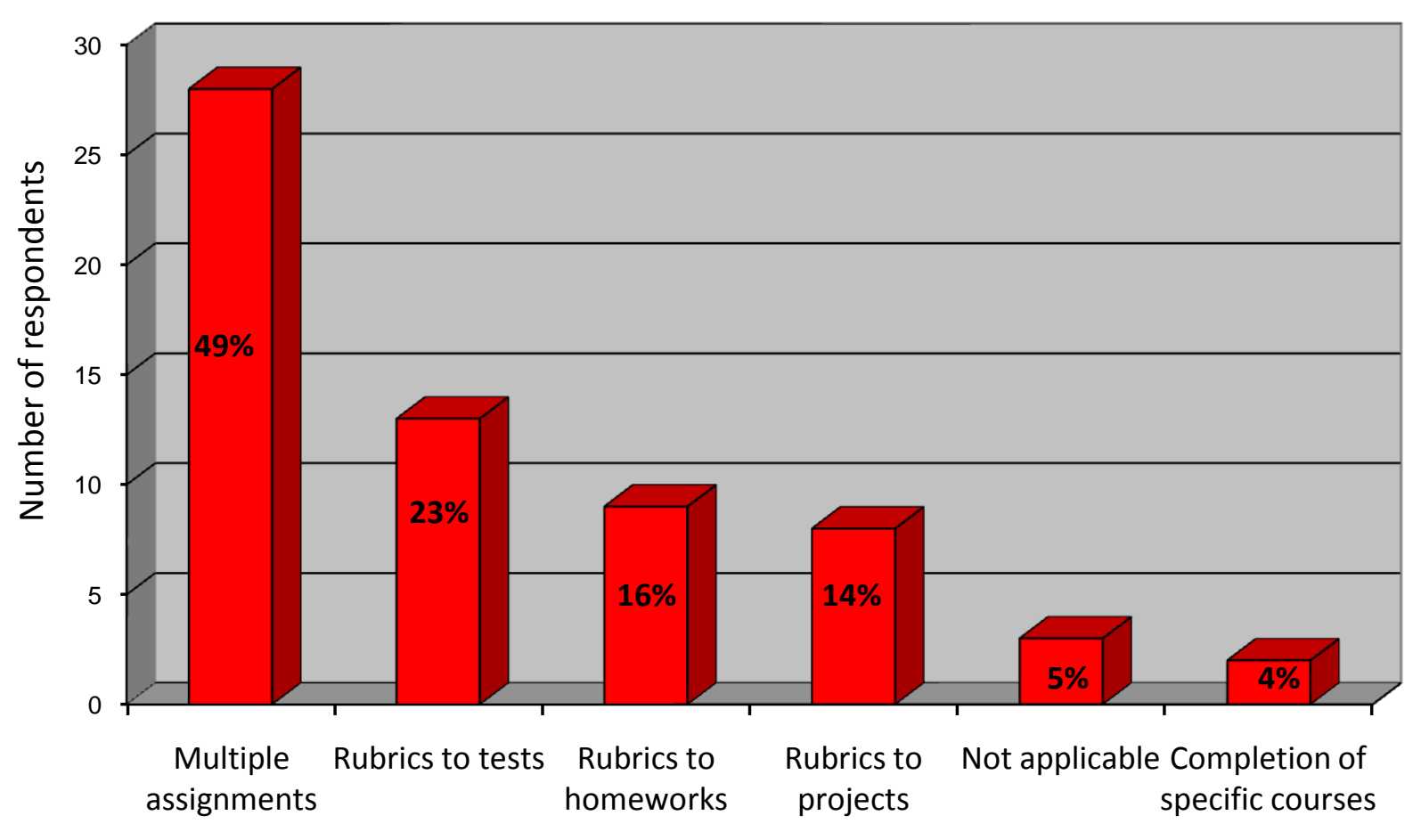

Figure 4: Measuring revised mathematics criterion within courses

Next, the survey asked participants, "How does your department plan to address the change ... requiring one additional area of basic science?" The findings indicated that the majority of respondents, 39 participants or $69 \%$, will either require one specific additional science class, such as geology, or have already met this requirement through their curriculum. It is notable that $32 \%$ of the respondents plan to allow their students to select which additional science to take as a required elective or selective. 


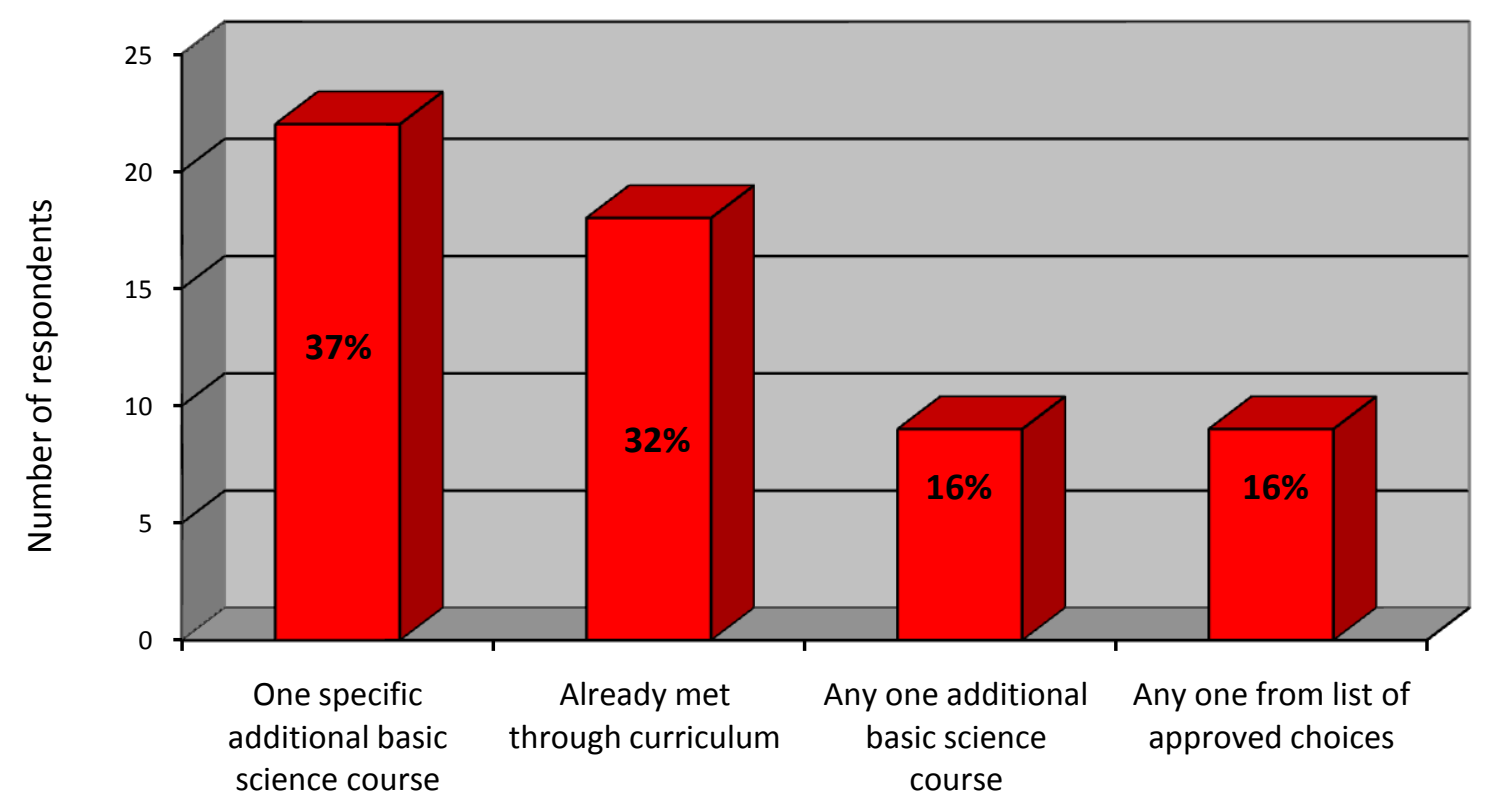

Figure 5: Responses for how departments are addressing revised science criterion

Next, the survey asked, "How is your department changing assessment methods to account for the change from measuring student 'proficiency' to the 'ability to apply knowledge'?" The responses shown in Figure 6 indicate that most (33 participants or 70\%) planned no changes. The $13 \%$ of respondents who chose the "other" category noted they would use traditional assessment methods such as evaluating learning objectives on specific problem solutions within homework or tests.

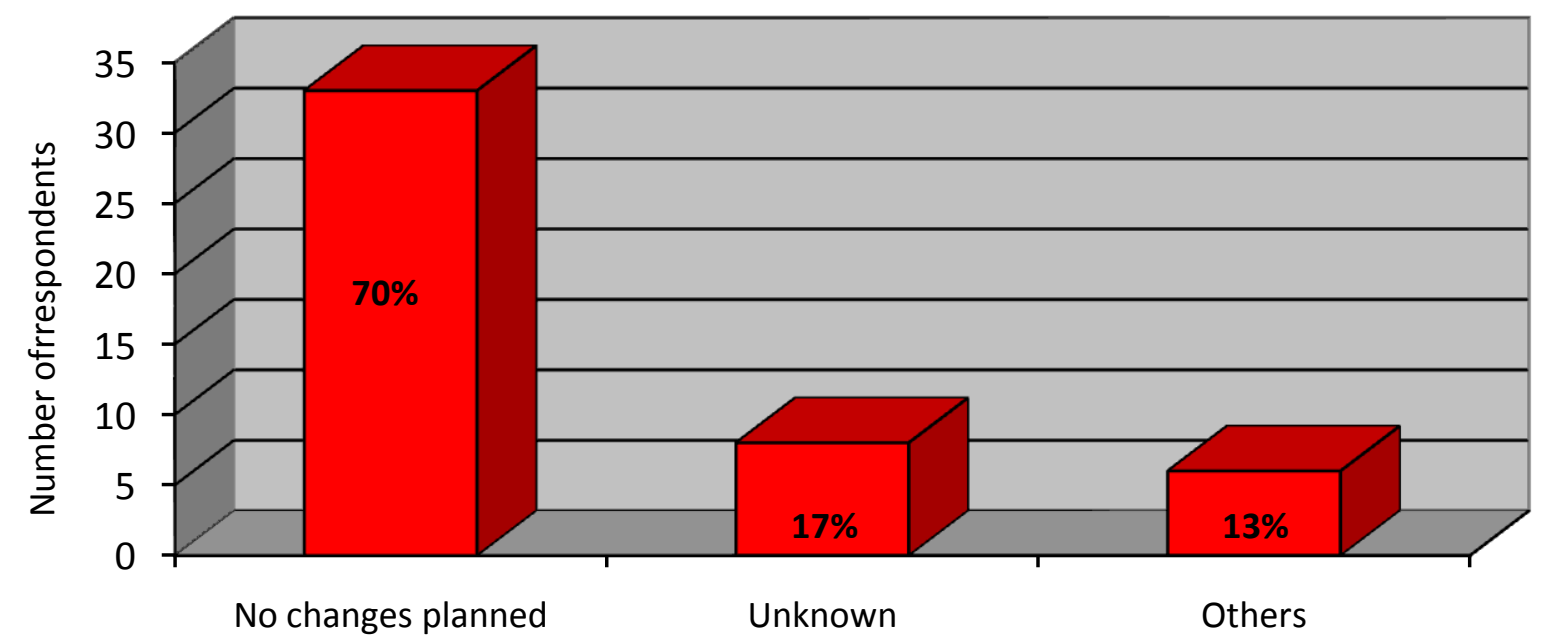

Figure 6: Changes planned between "proficiency" and "ability to apply knowledge" 


\section{Findings for Revised CE Technical Areas Program Criterion}

NEW: the ability to apply knowledge of four technical areas appropriate to civil engineering

PREVIOUS: proficiency in a minimum of four recognized major civil engineering areas

The next question in the survey focused on the changes in the wording of technical areas in the program criterion. Specifically, respondents were asked how they compare "the ability to apply" to "proficiency". As Figure 7 shows, nearly half (22 participants or 47\%) consider the two equivalent, several (15 participants or 32\%) consider "ability to apply" as easier to satisfy than "proficiency," and few (4 participants or 13\%) consider "ability to apply" as more difficult to satisfy.

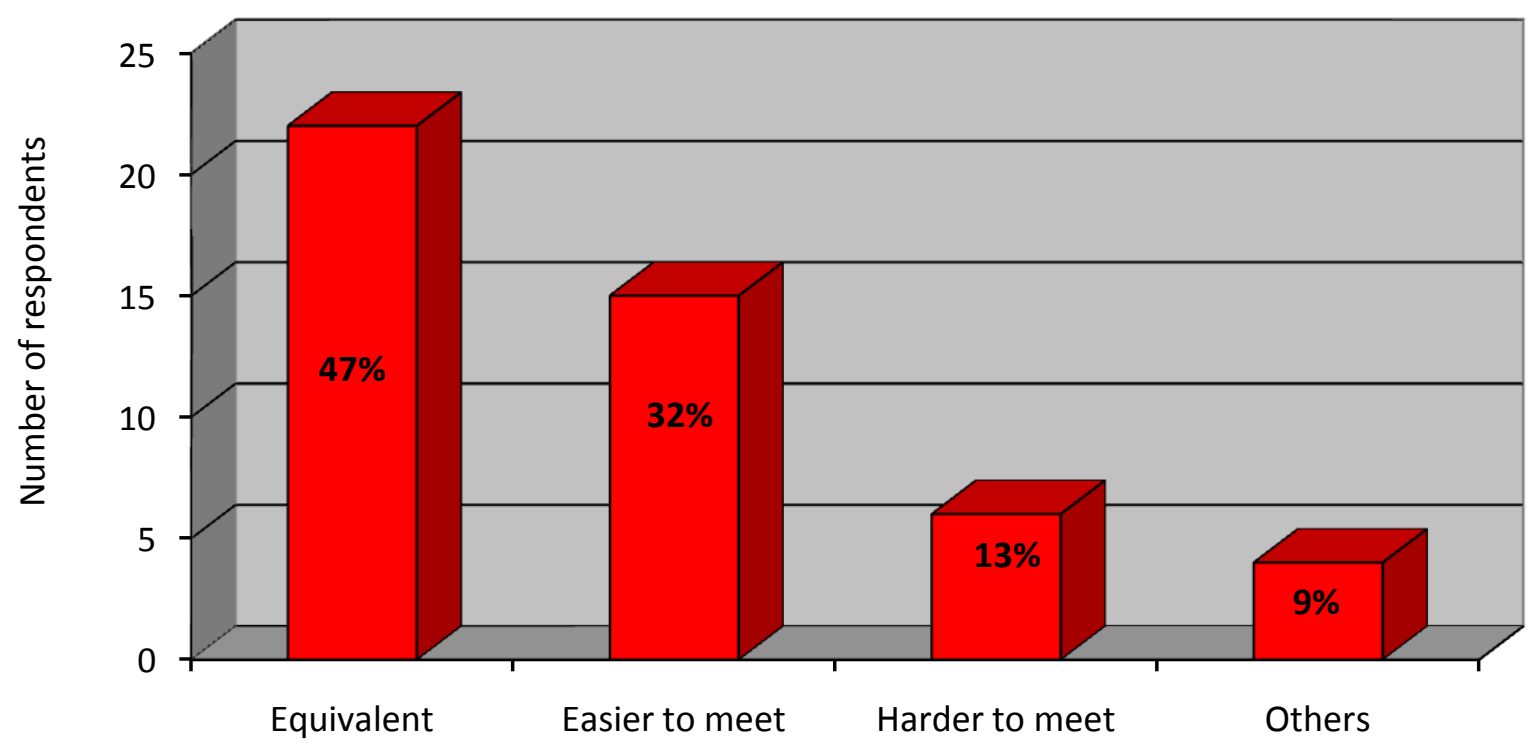

Figure 7: Interpretation of "Ability to Apply" versus "Proficiency" 


\section{Findings for Revised CE Design Program Criterion}

NEW: the ability to design a system, component, or process in more than one civil engineering context

PREVIOUS: an ability to perform civil engineering design by means of design experiences integrated throughout the professional component of the curriculum

The survey asked how departments interpreted the meaning of "context" in the revised criterion. The question allowed participants to select all that apply. As shown in Figure 8, 71\% of respondents interpreted this phrase as the ability of students to design in transportation, environmental, structural and geotechnical engineering. Respondents selecting the "others" category noted that "All the given options represent meaning of context," "meaning of context is unclear," and "context is not discipline."

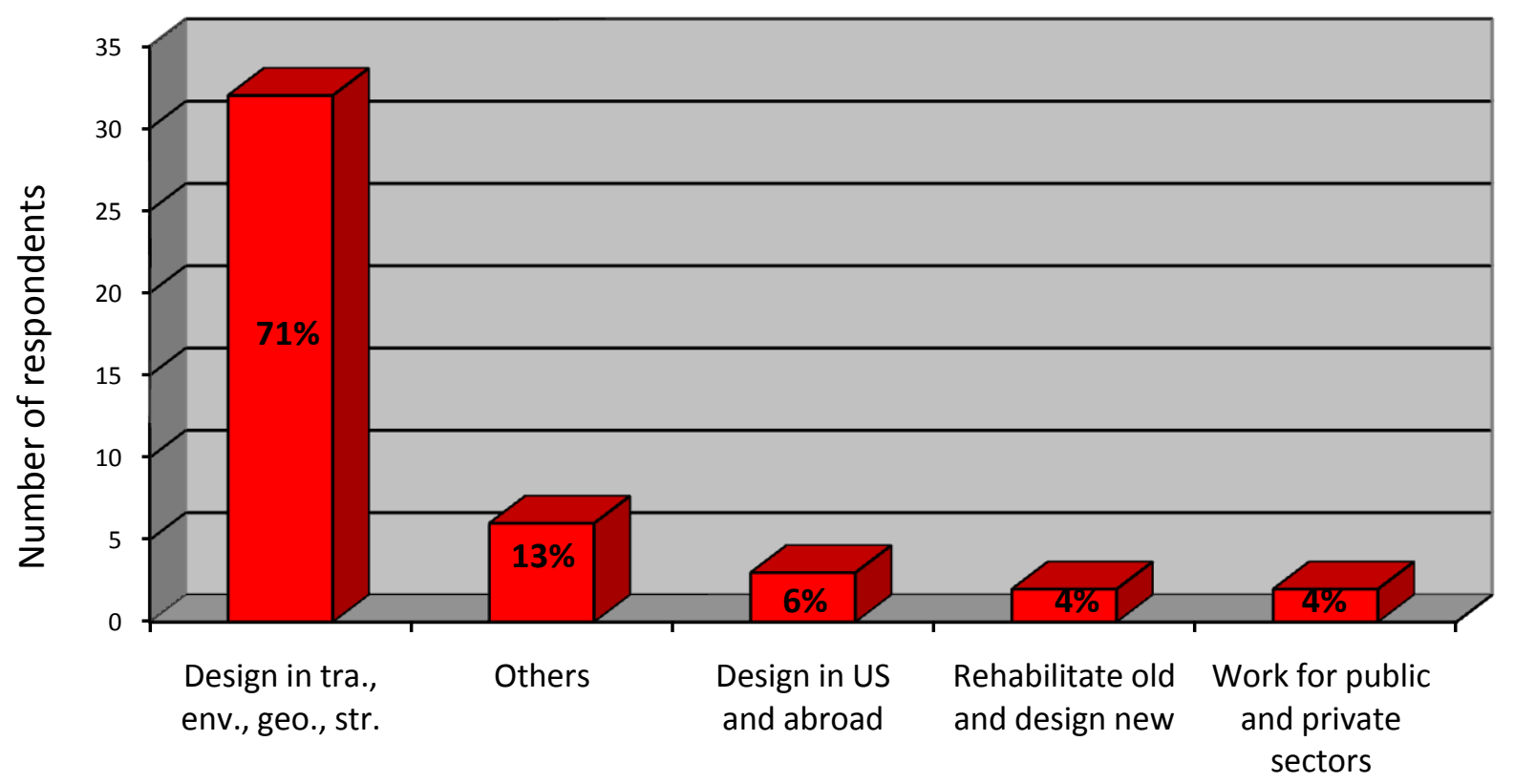

Figure 8: Interpreting the meaning of "context" 


\section{Findings for Revised CE Breadth Program Criterion}

NEW: the ability to explain basic concepts in management, business, public policy, and leadership; and explain the importance of professional licensure

PREVIOUS: an understanding of professional practice issues such as: procurement of work, bidding versus quality-based selection processes, how the design professionals and the construction professions interact to construct a project, the importance of professional licensure and continuing education, and/or other professional practice issues

The survey asked "Where does your department include/plan to include management, business, public policy, and leadership into the curriculum?" Figure 9 displays the varied opinions of the participants. Overall, 39 (68\%) chose "Capstone/senior design", 16 (28\%) chose "Student Chapter design project", and 14 (25\%) chose "Seminar courses." Fourteen choose both capstone and student chapter activities. These findings are not surprising when considering previous literature suggesting the great gains from student chapter and design project activities 20 .

In addition to the categories in Figure 9, respondents that selected the "other" category (13 or $23 \%$ ) recommended including basic concepts in required courses and even development of specific courses to meet these requirements. Examples of these new suggested courses included:

$>$ required senior level course in professional and legal issues

$>$ professional practice course

$>$ general engineering economics and ethics courses

$>$ engineering history and heritage course

$>$ ethics course and an engineering practice course

$>$ discussion of public policy in some of the CE courses. 


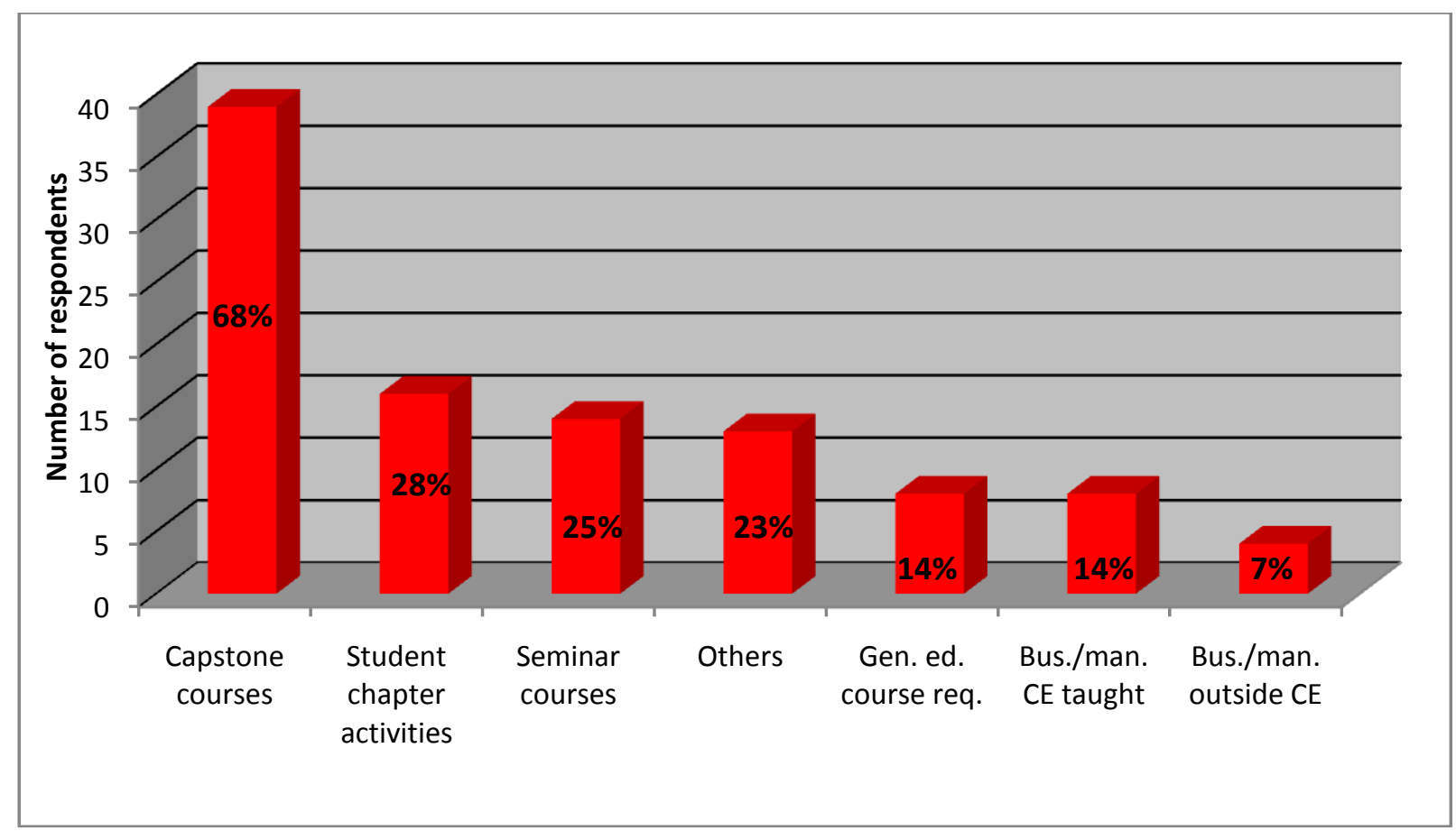

Figure 9: Inclusion of management, business, public policy and leadership into curriculum (Note: Because survey participants could select multiple categories, the percentages shown on the bars add to more than 100 percent. These percentages refer to how many selected each option compared to the total number of participants)

Next, the survey asked how departments plan to assess these changes. Figure 10 gives details about the response. Most commonly, $32(56 \%)$ respondents selected "assess outcomes in multiple courses," 26 (46\%) selected "assess outcomes on multiple assignments within a course," and 14 chose both. Apart from the options provided, other universities reported using alumni surveys, using capstone course work, FE exam results, graduation portfolios and student group activities. Respondents mentioned "the low level of cognitive development represented by being able to explain basic concepts" and "when evaluating public policy, leadership, ethics and professional registration one tool we use is an electronic discussion board." 


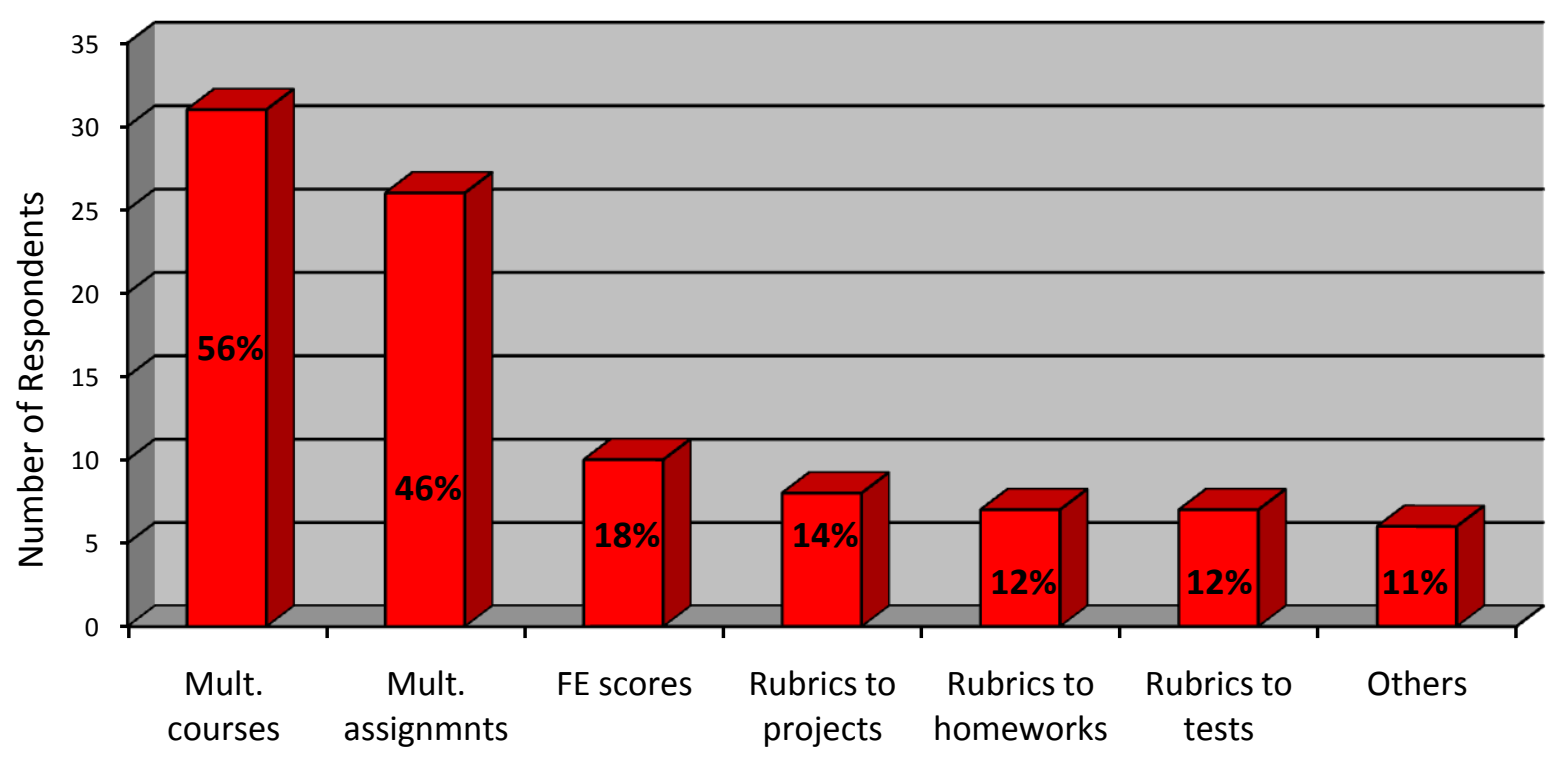

Figure 10: Plan of assessing management, business, public policy and leadership

(Note: Because survey participants could select multiple categories, the percentages shown on the bars add to more than 100 percent. These percentages refer to how many selected each option compared to the total number of participants)

\section{Conclusions}

This paper presents the results of a survey on ABET's latest revised program criteria for civil engineering. The results discussed here could be utilized by other departments and institutions for comparative purposes and to plan and implement changes in the curriculum to meet ABET's requirements.

Overall, few departments are executing or planning changes in response to the recent ABET CE Program Criteria changes. For the mathematics and science program criterion, many departments planned to assess using outcomes in multiple courses (72\%), on multiple assignments (49\%). Sixty eight percent reported the need to require an additional basic science course, albeit with varying specificity.

When assessing the Technical Areas Program Criterion, nearly half (47\%) considered both "ability to apply" and "proficiency" to be equivalent. Further, 78\% considered "context" as the ability to design in transportation, environmental, geotechnical, and structural sub-disciplines.

To meet the Breadth Program Criterion, capstone courses and student chapter activity were preferred forums for including the management, business, public policy and leadership in the curriculum. Previous studies support these types of student involvement, and few schools have developed additional specific courses to include these topics.

Overall, the most significant change reported was including an additional basic science course into the curriculum in response to the recent changes in the CE Program Criteria. Future work 
on this topic should focus on the ability of traditional assessment methods to capture the impact of these changes on student outcomes.

\section{Bibliography}

1. ASCE Body of Knowledge Committee of the Task Committee on Academic Prerequisites for Professional Practice. Civil Engineering Body of Knowledge for the 21st Century; ASCE: Reston, VA, 2004.

2. ASCE Body of Knowledge Committee of the Task Committee on Academic Prerequisites for Professional Practice. Second Edition of the Civil Engineering Body of Knowledge for the 21st Century; American Society of Civil Engineers: Reston, VA, 2008.

3. ABET, Inc. Criteria for accrediting engineering programs; ABET, Inc.: Baltimore, MD, 2011.

4. Koehn, E. Satisfying Body of Knowledge (BOK) Outcomes in an Undergraduate Curriculum. ASEE Annual Meeting, Chicago, IL, June 18-21, 2006.

5. $\quad$ Bilec, M. M.; Hendrickson, C.; Landis, A. E.; Matthews, H. S. Updating the Benchmark: Sustainable Engineering Report 2005-2010. ASEE Annual Meeting, Vancouver, BC, CA, June 26 - 29, 2011.

6. Burian, S. Teaching Sustainability and Sustainable Engineering Practice in The Civil Engineering Curriculum. ASEE Annual Meeting, Louisville, June 20 - 23, 2010.

7. Borrego, M.; Newwander, C. B.; McNair, L. D.; McGinnis, S.; Paretti, M. C. Using Concept Maps to Assess Interdisciplinary Integration of Green Engineering Knowledge. Advances in Engineering Education 2009, Winter.

8. Hayden, N. J.; Rizzo, D. M.; Dewoolkar, M. M.; Neumann, M. D.; Lathen, S.; Sadek, A.; Suny, B. Incorporating a Systems Approach into Civil and Environmental Engineering Curricula: Effect on Course Redesign, and Student and Faculty Attitudes. Advances in Engineering Education, Summer 2011.

9. Shuman, L.J., Besterfield-Cacre, M., and McGourty, J. The ABET "Professional Skills" - Can They be Taught? Can they be Assessed?. Journal of Engineering Education. January 2005.

10. Jones, D. K.; Baran, J. S.; Hsie, A. A new Course to Assess the Professionalism Skills Required by ABET. ASEE St. Lawrence Section 2011 Conference. March 18-19, 2011.

11. Welker, A. L.; Falcone, F. Professional Practices in Civil Engineering: Meeting and Exceeding the New Civil Engineering Program Criteria. Proceedings of the 2008 ASEE Annual Meeting, Pittsburgh, PA, June $22-25,2008$.

12. Welch, R. Humanities and Social Sciences Within Civil Engineering Curriculum. ASEE Annual Meeting, Vancouver, BC, CA. June 26 - 29, 2011.

13. Dahm, K.; Riddell, W.; Eric, C.; Harvey, R.; Courtney, J.; Lockette, P. V. Implementing and Assessing the Converging - Diverging Model of Design on a Sequence of Sophomore Projects. Advances in Engineering Education, Winter 2009.

14. Qualters, D. M.; Sheahan, T. C.; Mason, E. J.; Navick, D. S.; Dixon, M. Improving Learning in First - Year Engineering Courses through Interdisciplinary Collaborative Assessment. Journal of Engineering

Education, January 2008, 36-45. 
15. Swenty, B., Valenzuela, M., Allen, J., and Selvaraj, S.I., "Assessing Program Educational Objectives Using a Web-Based Alumni Survey System, " ASEE Annual Conference, Louisville, KY, June 20 - 23, 2010.

16. Felder, R. M.; Brent, R. Designing and Teaching Courses to Satisfy the ABET Engineering Criteria. Journal of Engineering Education 2003, January, 7-25.

17. Bielefeldt, A. Student Perceptions of the Civil Engineering Body of Knowledge. ASEE Annual Conference, Louisville, KY, June 20 - 23, 2010.

18. Koehn, E.; Mandalika, R. Curriculum Outcome Assessment using Subject Matter on the FE Examination.ASEE Annual Conference, Portland, Oregon June 12-15, 2005.

19. Nirmalakhandan, N.; Daniel, D.; White, K. Use of Subject - specific FE exam in Outcomes Assessment. Journal of Engineering Education 2004, January, 73-77.

20. Student Competitions and Experience Enhance ABET Requirements. American Society for Engineering Education Annual Conference \& Exposition, Salt Lake City, UT, June 20-23, 2004.

21. Masten, S. J., Chen, K., Graulau, J., Kari, S. L., and Lee, K.-H. A web-based and Group Learning Environment for Introductory Environmental Engineering. Journal of Engineering Education. January 2002. 69-80.

22. Ressler, S. J.; Lynch, D. R. The Civil Engineering Body of Knowledge and Accreditation Criteria: A Plan For Long-Term Management of Change. Vancouver, CA, June 26 - 29, 2011.

23. Koehn, E.; Malani, R. Satisfying ABET Accreditation: Program Assessment. Salt Lake City, UT, June 2023, 2004. 